\title{
OPTICAL INVESTIGATION OF A CAVITATING FLOW IN A 2D NOZZLE
}

\author{
Cyril Mauger \\ LMFA, CNRS UMR5509 \\ ECL, INSA, UCBL - Lyon, France
}

\author{
Marc Michard \\ LMFA, CNRS UMR5509 \\ ECL, INSA, UCBL - Lyon, France
}

\author{
Loïc Méès \\ LMFA, CNRS UMR5509 \\ ECL, INSA, UCBL - Lyon, France \\ Michel Lance \\ LMFA, CNRS UMR5509 \\ ECL, INSA, UCBL - Lyon, France
}

\author{
Stéphane Valette \\ LTDS, CNRS UMR5513 \\ ECL, ENISE - Lyon, France
}

\author{
Alexandre Azouzi \\ LMFA, CNRS UMR5509 \\ ECL, INSA, UCBL - Lyon, France
}

\section{SUMMARY}

In heat engines (vehicle), cavitation plays an important role in fuel atomization mechanisms. The physics of cavitation as well as its impact on spray formation and injector efficiency are not well documented yet. Experimental investigations are required. The complexity of modern injectors and the extreme conditions of injection do not facilitate experimental investigations. In this paper, experiments are conducted in a simplified geometry. The model nozzle consists of a transparent $2 D$ micro-channel supplied with a test-oil (ISO 4113). Velocity fields are obtained by means of a shadowgraph-like imaging arrangement using PIV components (double pulsed laser and double-frame camera). Pressure fields are obtained by interferometry coupled with a Schlieren technique.

\section{INTRODUCTION}

In modern internal combustion engines, diesel or gasoline is directly injected into the combustion chamber through a holetype nozzle with very high injection pressure, to produce a spray of fine droplets. Spray characteristics are crucial, since they determine the evaporation and mixing processes before combustion. In the nozzle holes, the flow is strongly accelerated and the pressure may drop down to the fuel vapor pressure, leading to cavitation. Cavitation is generally regarded as a source of problems: noise, vibrations, efficiency loss and damage. In the particular case of fuel injection, it leads to a flow rate limitation. However, cavitation offers some advantages by preventing nozzles from fouling and possibly enhancing atomization processes. As shown in the early work by Bergwerk [1], the fully developed cavitation regime, known as hydraulic flip, in the injector hole may increase the break-up length at the injector outlet. On the contrary, in other cavitation regimes, liquid atomization can be enhanced [2,3]. Several studies have highlighted the influence of various parameters on cavitation inception: inlet radius [4], hole taper [5, 6] and hole roughness [5, 7]. Nevertheless, our understanding of cavitation inception and its consequences in injectors remain insufficient. Further investigations are needed to clarify the mechanisms of cavitation inception and to provide detailed experimental data to be compared with CFD computation. The experimental study of nozzle cavitation in real conditions is difficult. Nozzles must be transparent, and resist to high injection pressure and shocks caused by the needle lift. As a consequence, only a few experimental studies have been done in realistic conditions [8] while most have been conducted on simplified geometries: up-scaled nozzles, lower pressure and lower velocity... In the present paper, a study of cavitation in a $400 \mu \mathrm{m}$ high $2 \mathrm{D}$ channel is presented. Such a simplification has been already adopted in previous works $[9,10]$. It provides several advantages in terms of optical access and image interpretation. In the present case, the $2 \mathrm{D}$ geometry also helps to control and characterize the channel geometry and surface roughness. The channel flow is visualized by using shadowgraph-like technique and interferometric imaging, as a function of the inlet/outlet pressure drop.

\section{EXPERIMENTAL SETUP Channel design}

In the present study, cavitation is investigated in a quasi-2D orifice (channel). The channel consists of two separated metal sheets, sandwiched between a pair of glass windows (Figure 1). The channel is continuously supplied with fuel (test oil SHELL V-Oel-1404) through holes directly drilled into the glass windows. Oil pressure levels are measured $40 \mathrm{~mm}$ upstream and downstream of the channel using metal thin film sensors. A variable area meter measures the flow rate. Oil temperature is regulated by a air/oil heat exchanger and controlled by a T-type thermocouple.

The use of two separated metal sheets makes it possible to better control channel geometry and wall roughness. A Scanning Electron Microscope (SEM) has been used to measure channel dimensions. Channel is about $400 \mu \mathrm{m}$ high and 1,475 $\mu \mathrm{m}$ long, with an area reduction of $5 \%$ between the inlet and the outlet. The channel depth is $L=2 \mathrm{~mm}$. The surfaces constituting the channel walls have been mirror-polished. Their roughness has been characterized with an optical profilometer $\left(R_{a}<0.1 \mu \mathrm{m}\right)$. 


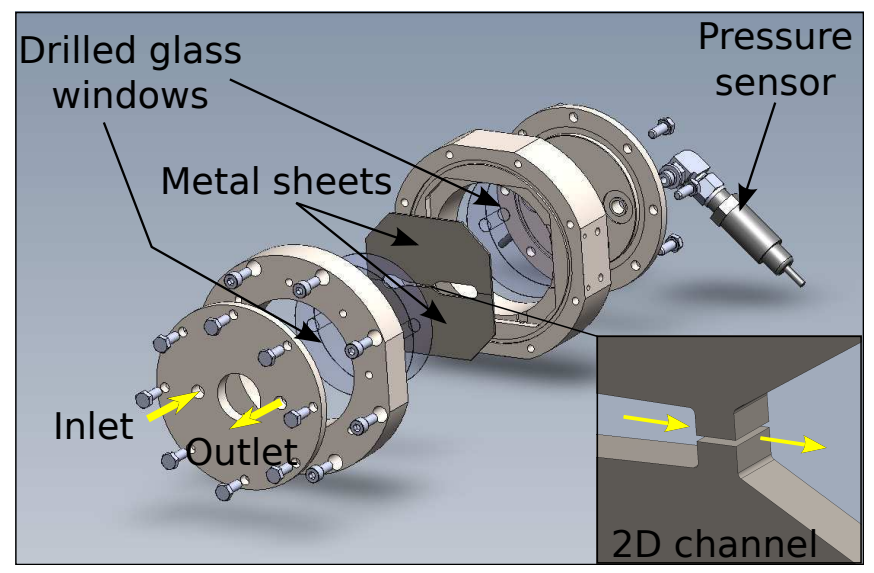

Figure 1. Exploded view of the 2D micro-channel.

Depending on the pressure difference $\Delta p$ between the channel inlet and outlet, three flow regimes have been identified, namely single-phase flow, cavitating flow and choked flow. Cavitating flow must be divided in three steps: Cavitation inception, cavitation development and super-cavitation.

The channel flow has been visualized using PIV and interferometry (coupled with Schlieren) methods. Optical techniques are presented in the following section.

\section{Optical arrangement for PIV and image processing}

The small size of the channel requires the use of large optical magnification. With flow velocities up to $70 \mathrm{~m} . \mathrm{s}^{-1}$, an extremely short light pulse is needed to optically freeze the flow. In addition, an incoherent light source is necessary to avoid speckle on images. Figure 2 presents the optical arrangement used. An adequate light source is generated by focusing the second harmonic of a Nd:YAG pulsed laser (wavelength $\lambda_{Y A G}=532 \mathrm{~nm}$ and pulse duration (6 ns) on a fluorescent polymethyl-methacrylate (PMMA) sheet. The fluorescent emission is collimated and the remaining laser light is filtered using a band reject filter (Notch filter $\lambda_{\text {Notch }}=533 \pm 8 \mathrm{~nm}$ ). The Nd:YAG dual head laser helps to produce time delayed light pulses. Each pulse lasts $12 \mathrm{~ns}$ (FWHM) and has a broad spectrum (about $100 \mathrm{~nm}$ ). The time delay between both pulses can be adjusted, down to about $\Delta t_{P I V \text { min }} \approx 30 \mathrm{~ns}$. Images are recorded by means of an optical zoom (OPTEM 125C) on a $2048 \times 2048$ px $^{2} 10$-bit CCD camera. The resulting magnification is $1.15 \mu \mathrm{m} . \mathrm{px}^{-1}$. Using the doubleframe mode of the camera and the dual pulse system of the laser, couples of images separated by $\Delta t_{\text {cam } \min } \approx 200$ ns or more are recorded. This optical arrangement permits the tracking of rapid events, like bubble dynamics, and the production of velocity information.

Figure 3 displays two examples of instantaneous images in a single phase flow and cavitating flow. Bright areas correspond to liquid phases whereas dark areas correspond to vapor formations or walls. Grey-level variations are also observed, due to shadowgraph effects revealing density (refractive index) gradients. Density gradients are associated to pressure or/and temperature variations. The optical arrangement can therefore be viewed as a backlit imaging arrangement which is sensitive to density

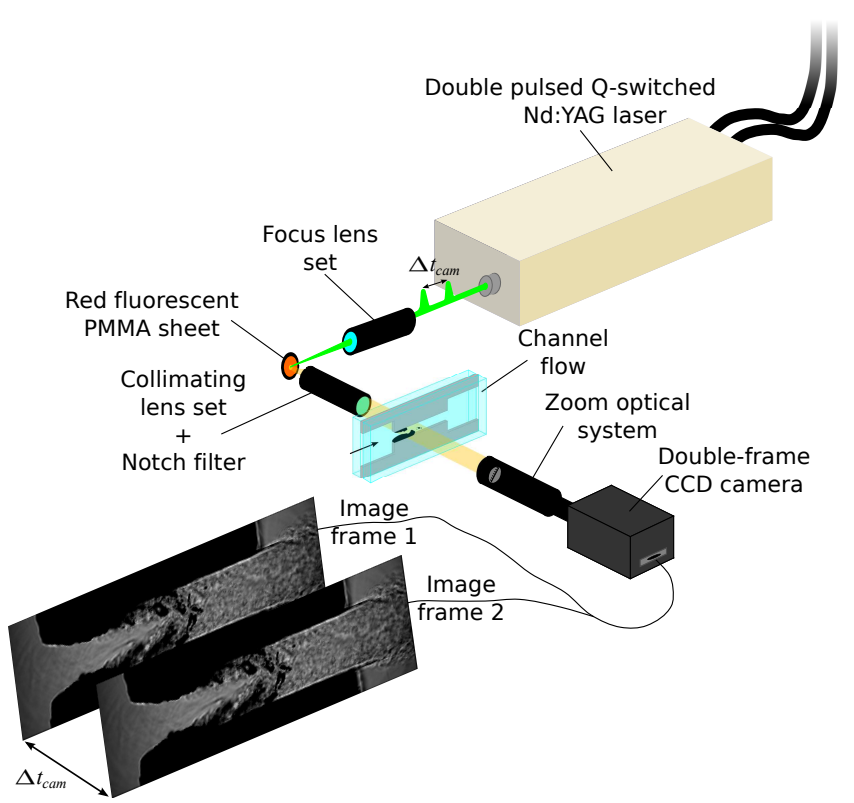

Figure 2. Shadowgraph-like imaging arrangement for PIV measurements.

gradients. Figure 3 reveals:

a- streamlines (density gradients) originating from a thermal marking of the flow, far upstream from the channel,

b- shear layers at the corner due to a density difference between the recirculation zones and the main flow,

c- out-going jet boundaries. Both temperature and pressure gradients are involved. The temperature gradient would be due to the viscous heating of the fluid near the walls. The pressure gradient would be associated to the pressure difference between the out-going jet and the downstream chamber,

d- grey-level random-like variations in the wake of the recirculation zones. They appear as structures developing from the walls to the center of the channel where they join together. They are the sign of turbulence and associated density fluctuations,

e- cavitation formation at the inlet of the channel,

f- vapor bubble detachments.

In each couple of images, the turbulent structure displacement can be seen. In order to measure it, images are crosscorrelated using a PIV algorithm [11,12]. The PIV processing is realized by three successive passes with decreasing interrogation window size (i.e. $128 \times 128 \mathrm{px}^{2}, 64 \times 64 \mathrm{px}^{2}$ and $24 \times 24 \mathrm{px}^{2}$ ). The spacing between each interrogation window for the last pass is 12 px. After the PIV processing, structure displacement is known. A data post-processing is required to eliminate displacement information resulting from zones that are free from structures. The post-processing is applied when the standard deviation of grey-levels in an interrogation window is below a critical value (typically 5). Channel dimensions are well known thanks to SEM visualizations and the time between two light pulses has been accurately measured with a photodiode. Displacement information can therefore be converted into velocity information. Figure 4 presents an example of PIV processing. 


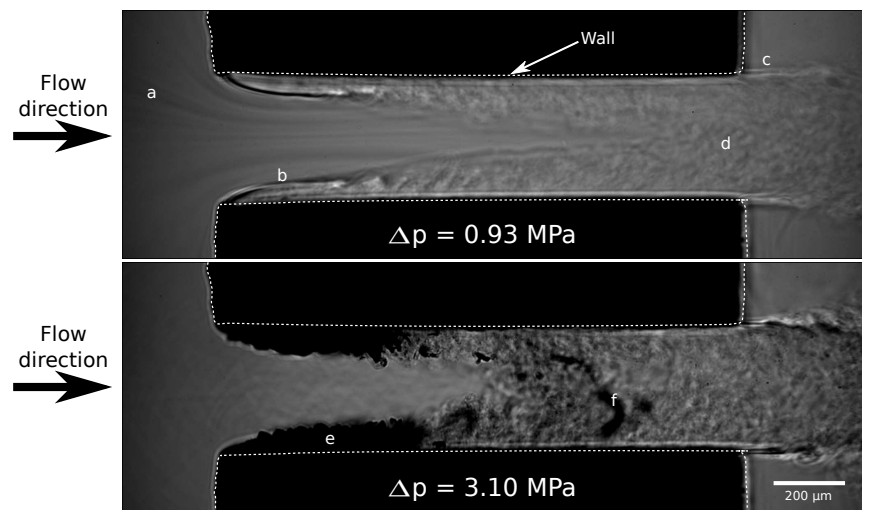

Figure 3. Shadowgraph-like images in a $400 \mu \mathrm{m}$ high 2D channel, $p_{u p}=5.00 \mathrm{MPa}, T \approx 48^{\circ} \mathrm{C}$. At the top: Single phase flow. At the bottom: Cavitating flow.

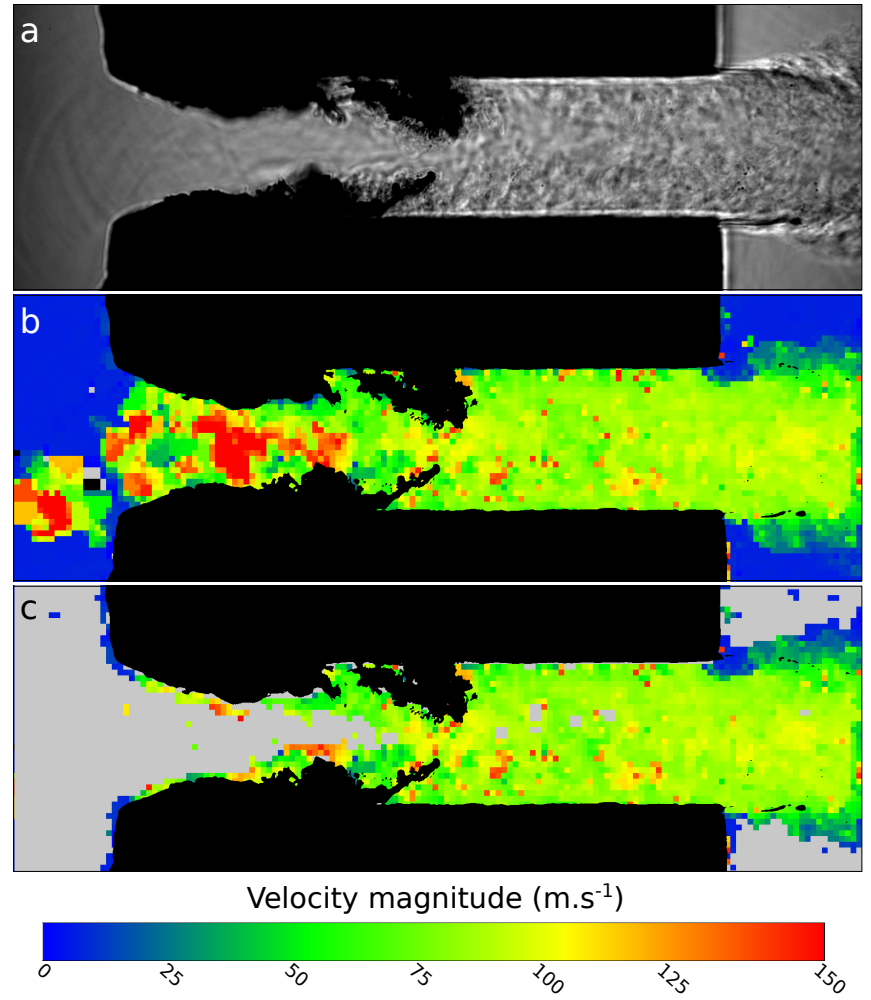

Figure 4. a: Instantaneous visualization of a $400 \mu \mathrm{m}$ high $2 \mathrm{D}$ channel. b: PIV processing. c: Post-processing. $p_{u p}=5.00 \mathrm{MPa}$, $p_{\text {down }}=1.69 \mathrm{MPa}, T=32^{\circ} \mathrm{C}$.

\section{Interferometric arrangement and density field recon-} struction

An interferometric arrangement (Mach-Zehnder interferometer) is used to measure pressure fields inside the channel. This method is based on phase shift measurement, and is therefore sensitive to the refractive index (or density). The optical arrangement is presented in Figure 5. An argon-ion laser $\left(\lambda_{A r}=514 \mathrm{~nm}\right)$ in continuous wave operation is used as the light source. The beam size is magnified and spatially filtered using two convergent lenses and a pin-hole filter. A beam splitter divides the beam into a reference beam and a measurement beam which illuminates the channel flow. Both beams are recombined using a second beam splitter and transmitted through the camera lens. As continuous illumination is used, the time resolution of images is limited by the minimum exposure time of the camera $(20 \mu \mathrm{s})$.

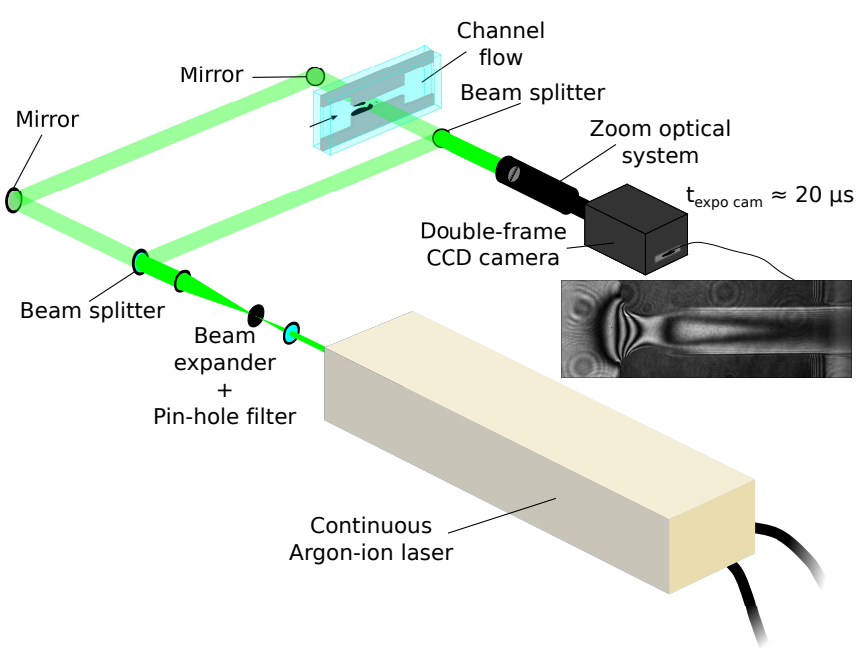

Figure 5. Interferometric arrangement for density field measurements.

Figure 6 presents an example of interferograms. Images show a fringe pattern which depends on density fields. Optical rays (measurement beam) passing through the channel flow are phase shifted, depending on the refractive index (or density). The recombination of the measurement beam with the reference beam leads to constructive or destructive interferences. The succession of bright and dark fringes is the sign of density evolution throughout the channel: At channel inlet, where pressure decreases rapidly, in recirculation zones (for the lower pressure drop) and at channel outlet. For increased pressure drops (Figure $6 \mathrm{~b}$ ), the distance between fringes decreases throughout the channel, as density gradients increase. In interferograms, channel walls and vapor cavities appear in grey, as only the reference beam contribute to images in these areas (Figure 6b).

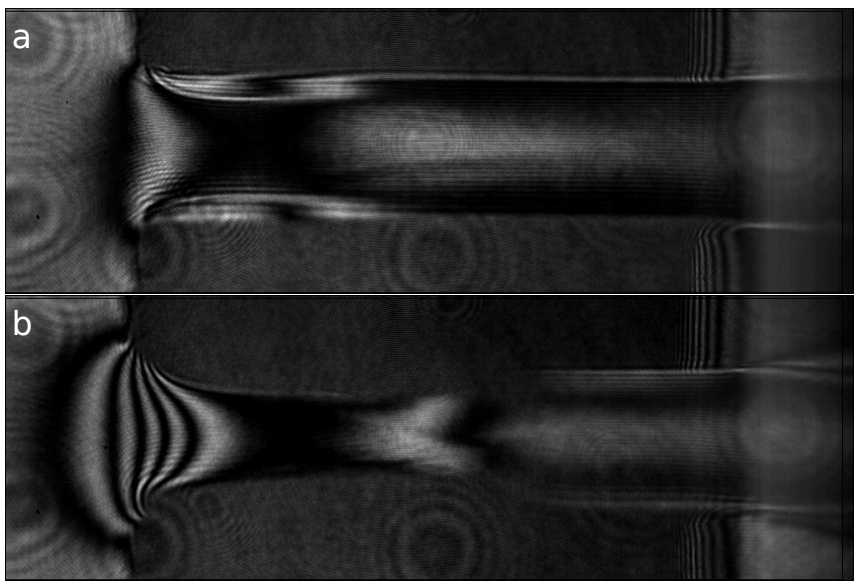

Figure 6. Example of interferograms in a $400 \mu \mathrm{m}$ high 2D channel. $p_{\text {amont }}=5.00 \mathrm{MPa}$. a: $\Delta p=0.97 \mathrm{MPa}$. b: $\Delta p=3.50 \mathrm{MPa}$. 
The optical path shift between a bright and a dark fringe is:

$$
\Delta n=\frac{\lambda_{A r}}{2 L}
$$

To relate refractive index $n$ to flow density $\rho$, the LorentzLorenz relation is used:

$$
\frac{n^{2}-1}{n^{2}+2}=K \rho
$$

where $K$ is a constant which depends only on material (the test oil). The refractive index has been measured by using a refractometer (NAR-1T): $n_{0}=1.462$ for density $\rho_{0}=820 \mathrm{~kg} \cdot \mathrm{m}^{-3}$ ( $p=0.1 \mathrm{MPa}$ and $T=20^{\circ} \mathrm{C}$ ). The density has been deduced from measurement of oil properties [13].

As a rule, when a density condition (upstream in the present case) is known, density fields can be deduced from interferograms by counting the number of fringes. However, such a construction is difficult in practice as the sign of the fringe shift is unknown. In other words, the density change between a dark and a bright fringe can be interpreted as an increase of $+\delta p$ or a decrease of $-\delta p$. This ambiguity may be solved using Schlieren imaging [14]. This technique provides qualitative evolution of gradient index. Thanks to the Schlieren imaging results, density fields can be reconstructed (Figure 11). Density fields are presented with both density scaling bar and pressure scaling bar. The pressure scaling is a direct translation of density in terms of pressure, under the assumption of constant temperature.

\section{RESULTS AND DISCUSSION}

The PIV processing is applied on series of 50 images recorded in the same conditions. In Figure 7, streamwise velocity profiles $\overline{U_{x}}$ are averaged over a series of images at different locations inside the channel $(15,40,65$ and $90 \%$ of the channel length).

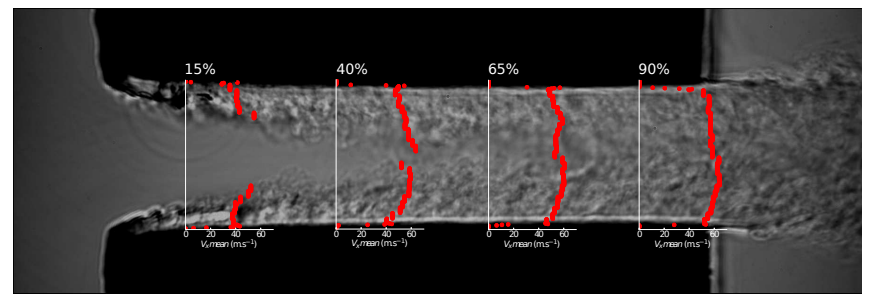

Figure 7. Streamwise mean velocity $\overline{U_{x}}$ profiles in a $400 \mu \mathrm{m}$ high $2 \mathrm{D}$ channel. $p_{\text {up }}=5.00 \mathrm{MPa}, p_{\text {down }}=2.48 \mathrm{MPa}, T=48^{\circ} \mathrm{C}$ (Instantaneous visualization of cavitation inception).

The location of each velocity profile corresponds to the ordinate axis of each graph. Velocity profiles show that structures accelerate along the channel and reach a maximum at the outlet. The output velocity profile is almost flat.

The cross-streamwise velocity $\overline{U_{y}}$ profiles averaged over the series of images (not presented in the paper) show that turbulent structures located behind the recirculation zones move to the channel center faster than the structures at the channel outlet. When boundary layers merge, cross-streamwise velocity is almost equal to 0, which shows that the flow is well established. At the channel outlet, turbulent structures move essentially in the flow direction.

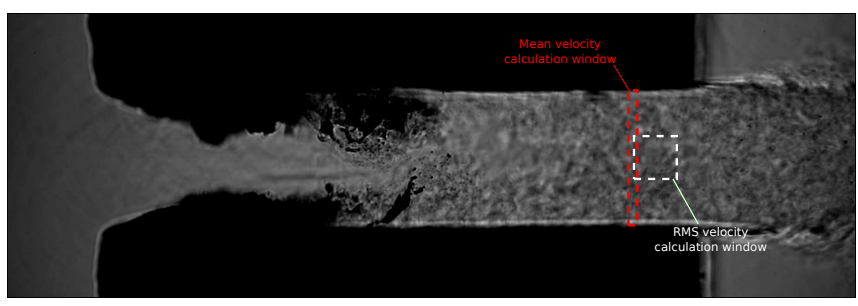

Figure 8. Calculation window in the channel for mean velocity and RMS velocity in a $400 \mu \mathrm{m}$ high $2 \mathrm{D}$ channel. $p_{u p}=5.00 \mathrm{MPa}$, $p_{\text {down }}=1.20 \mathrm{MPa}, T=48^{\circ} \mathrm{C}$.

The mean velocity of the turbulent structures is calculated for streamwise component $\left(\overline{U_{x}}\right)$ at the channel outlet (Figure 8). Information from black areas, corresponding to wall or cavitation, is not considered in the mean calculation. The mass flow rate deduced from $\overline{U_{x}}$ is compared to the mass flow rate measured experimentally (Figure 9a). PIV mass flow rate values underestimate the mass flow rate (flowmeter) by about $6 \%$. At the channel outlet, the structure velocity is almost equal to the flow velocity. The difference between both velocities is bigger when the flow is choked: Vapor cavities reach the channel outlet and structure velocity decreases (Figure 9b).

In Figure $9 \mathrm{~b}, \overline{U_{y}}$ is plotted. The channel flow is supposed to be symmetric; half the absolute cross-streamwise mean velocity is used for $\overline{U_{y}}$ values. $\overline{U_{y}}$ decreases when the flow is single-phase and reaches a minimum value at cavitation inception. Then, for $\sqrt{\Delta p}>1.576 \mathrm{MPa}^{0.5}$ (cavitation development phase), $\overline{U_{y}}$ keeps roughly constant. In the choked flow regime, $\overline{U_{x}}$ decreases and $\overline{U_{y}}$ seems to increase at the same time. In real injection configuration, the primary break-up of the liquid jet mainly depends on the outlet velocity field and flow turbulence [15-17]. An increase in the radial velocity component may influence fuel atomization. Moreover, when cavitation occurs, vapor bubble collapse, which may increase turbulence at the injector outlet and participate to the early deformations of the liquid jet $[15,16,18,19]$.
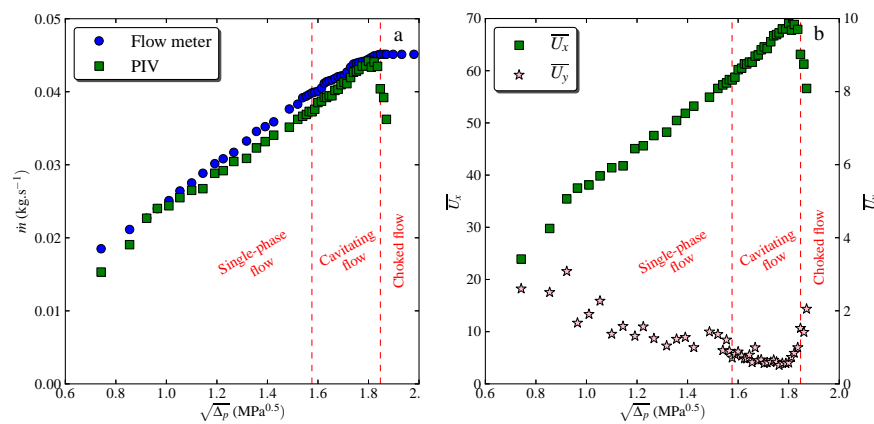

Figure 9. a: Comparison between the mass flow rate deduced by flowmeter and PIV measurement. b: Streamwise and cross-streamwise mean velocities (PIV) at the channel outlet. $400 \mu \mathrm{m}$ high 2D channel. $p_{u p}=5.00 \mathrm{MPa}, T=48^{\circ} \mathrm{C}$. 

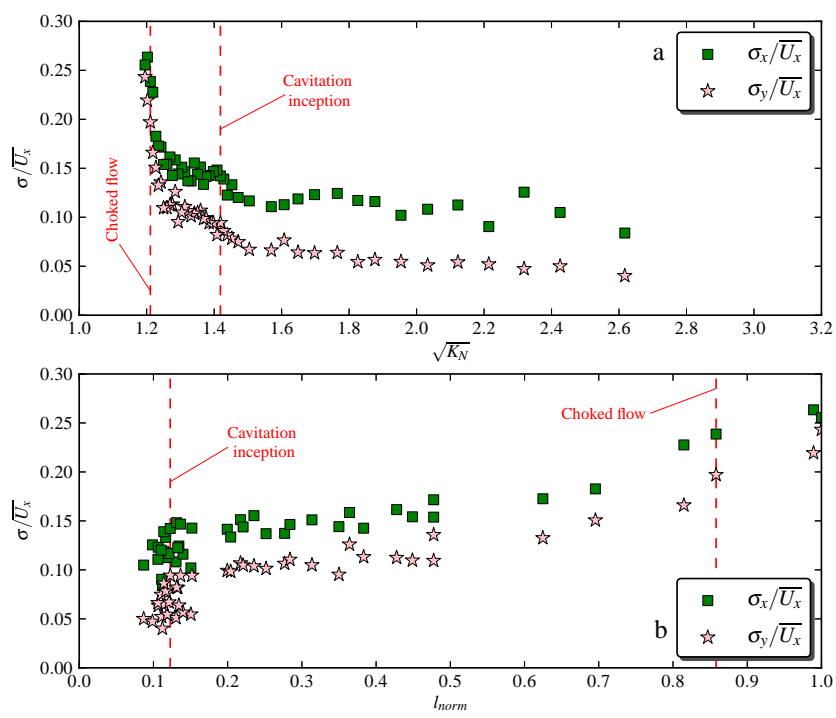

Figure 10. a: Relative velocity fluctuations versus square root of the cavitation number $\sqrt{K_{N}}$. b: Relative velocity fluctuations versus normalized vapor cavity length $l_{\text {norm }}$. $400 \mu \mathrm{m}$ high $2 \mathrm{D}$ channel. $p_{\text {up }}=5.00 \mathrm{MPa}, T=48^{\circ} \mathrm{C}$.

The experimental setup used does not make it possible to study the influence of the internal flow on the spray formation because the discharge volume is liquid. Nevertheless, velocity fluctuations at the channel outlet can be investigated. For a particular flow area (Figure 8 , in white), the relative root mean square (RMS) of velocity $\sigma / \overline{U_{x}}$ is plotted against Nurick cavitation number $\sqrt{K_{N}}$ (Figure 10a) and normalized length of vapor cavities $l_{\text {norm }}$ (Figure 10b). Nurick cavitation number is defined as:

$$
K_{N}=\frac{p_{u p}-p_{\text {vap }}}{p_{\text {up }}-p_{\text {down }}}
$$

$l_{\text {norm }}$ is statistically obtained from a series of images at each flow condition. $l_{\text {norm }}=0$ means that no cavitation (or density gradient) occurs inside the channel and $l_{\text {norm }}=1$ means that vapor cavities reach the channel outlet. The streamwise and cross-streamwise relative root mean square of velocity evolves in the same way but $\sigma_{y} / \overline{U_{x}}$ is lower than $\sigma_{x} / \overline{U_{x}}$. From $\sqrt{K_{N}}=2.617$ to cavitation inception $\left(\sqrt{K_{N}}=1.419\right)$ (right to left for decreasing $\sqrt{K_{N}}$ ), the relative root mean square of velocity remains almost constant for streamwise and cross-streamwise components. During cavitation growing $\left(1.419>\sqrt{K_{N}}>1.293\right)$, both component fluctuations increase slightly. From $\sqrt{K_{N}}=1.293$ to $\sqrt{K_{N}}=1.158$ (i.e. $0.35<l_{\text {norm }}<1$ ), relative fluctuations increase by more than $40 \%$. Thus, the flow (velocity fluctuations) at the outlet seems to be strongly affected by cavitation when vapor cavities reach one third of the channel. This suggests that vapor formation may improve fuel atomization by increasing velocity fluctuations at the injector outlet, even if super-cavitation is not reached yet.

Density fields are reconstructed from interferograms (Figure 11). At the centerline, for all pressure drop conditions, pressure decreases rapidly at the channel inlet to reach a minimum lo- cated at the minimum section imposed by the flow contraction or the vapor cavities. Then, pressure increases to a local maximum and decreases slowly again until the channel outlet. The minimum pressure point slowly moves toward the channel exit as the pressure drop increases (Figure 11a-b). The minimum pressure value at the channel centerline decreases with increasing pressure drop but it remains always greater than the downstream pressure, including in the choked flow condition. The lowest pressure is located in the recirculation zones. In Figure $11 \mathrm{c}-\mathrm{d}$, pressure is found to be almost equal to $0( \pm 0.15 \mathrm{MPa})$ at the inlet corner but cavitation incepts relatively far from the inlet corner, in the shear layer (Figure 11d). Shadowgraph-like and Schlieren images (not presented here), reveal strong instabilities developing in the shear layers before cavitation inception [14]. Cavitation could incept under the joint effect of decreasing pressure in recirculation zones and instabilities developing in the shear layer.

\section{CONCLUSIONS}

The pressure and velocity fields of a cavitating flow in a $400 \mathrm{~m}$ high nozzle have been obtained using a shadograph-like technique and interferometry. An increase in cross-streamwise velocity $\overline{U_{y}}$ has been observed at the channel outlet, when the flow was choked. Velocity fluctuations $\sigma / \overline{U_{x}}$ at the channel outlet have increased as soon as the length of vapor cavities reached more than a third of the nozzle $\left(l_{\text {norm }}>0.35\right)$. Pressure fields have shown that cavitation does not incept at the channel inlet but further in the shear layers.

\section{ACKNOWLEDGMENTS}

This work takes place in the French collaborative program NADA-bio (New Advanced Diagnosis for Diesel Injection Analysis and bio fuels), supported by DGCIS (French government), Région Haute Normandie, Conseil Général des Yvelines and Movéo.

\begin{tabular}{|c|c|c|c|}
\hline \multicolumn{4}{|c|}{ NOMENCLATURE } \\
\hline$\Delta p:$ & $p_{\text {up }}-p_{\text {down }}$ & $p_{\text {vap }}:$ & Oil vapor pressure \\
\hline$\Delta t:$ & Time delay & $\rho:$ & Oil density \\
\hline$\lambda:$ & Wavelength & $R_{a}:$ & Arithmetical mean \\
\hline$l_{\text {norm }}:$ & $\begin{array}{l}\text { Normalized length of } \\
\text { vapor cavities }\end{array}$ & & $\begin{array}{l}\text { roughness } \\
\text { Oil temperature }\end{array}$ \\
\hline$L:$ & Channel depth & $\overline{U_{x}}:$ & Mean streamwise \\
\hline$K:$ & Lorentz-Lorenz law & & velocity \\
\hline & constant & $\overline{U_{y}}:$ & Mean cross- \\
\hline$K_{N}:$ & Nurick cavitation number & & streamwise velocity \\
\hline $\begin{array}{l}\dot{m}: \\
n:\end{array}$ & $\begin{array}{l}\text { Mass flow rate } \\
\text { Oil refractive index }\end{array}$ & $\sigma_{x}$ & $\begin{array}{l}\text { Streamwise RMS } \\
\text { velocity }\end{array}$ \\
\hline$p_{\text {down }}:$ & Downstream pressure & $\sigma_{y}:$ & Cross-streamwise \\
\hline$p_{\text {up }}$ & Upstream pressure & & is velocity \\
\hline
\end{tabular}

\section{REFERENCES}

[1] Bergwerk, W., 1959. "Flow pattern in diesel nozzle spray holes". Proceedings of the Institution of Mechanical Engineers 1847-1982 (vols 1-196), 173(1959), pp. 655-660.

[2] Tamaki, N., Shimizu, M., and Hiroyasu, H., 2001. "Enhancement of the atomization of a liquid jet by cavitation in a nozzle hole". Atomization and Sprays, 11(2), pp. 125137. 

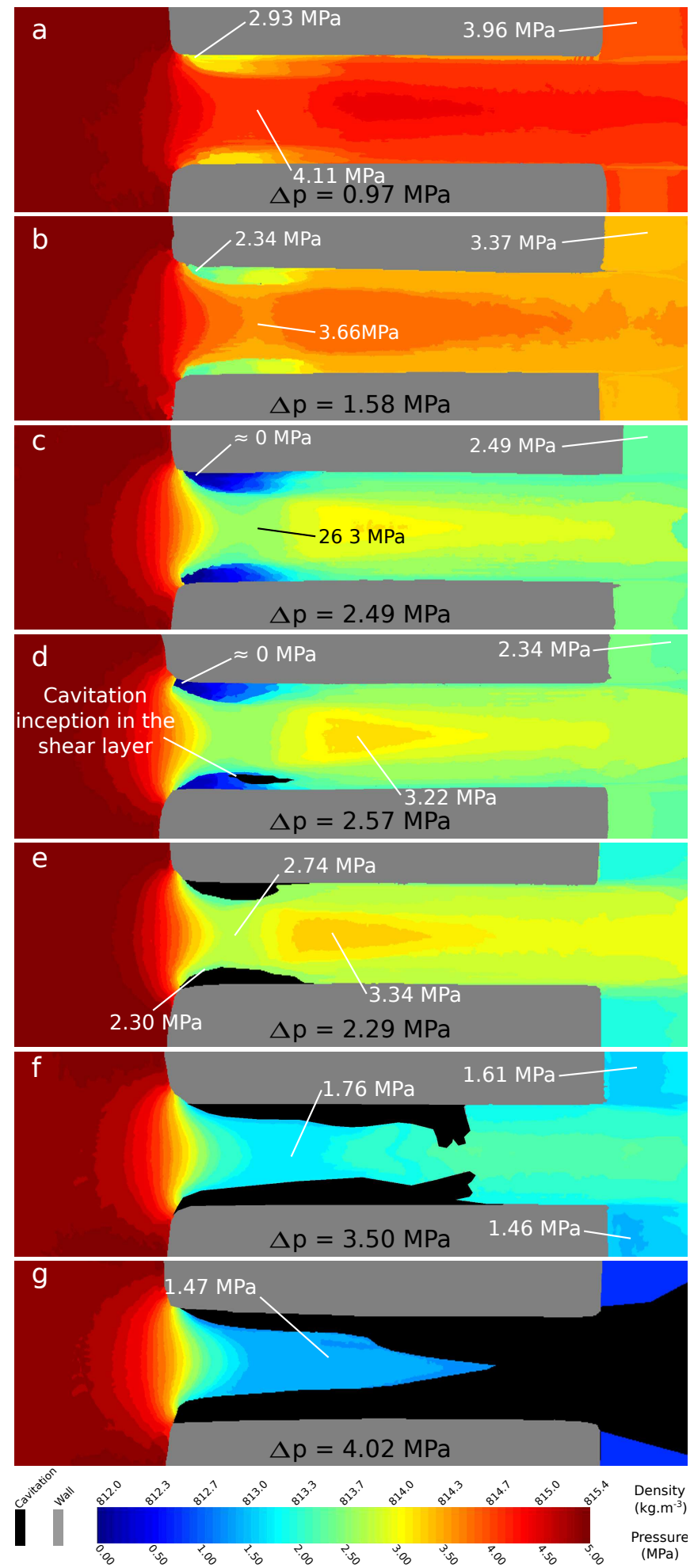

Figure 11. Examples of interferogram reconstruction in a $400 \mu \mathrm{m}$ high 2D channel. $p_{\text {amont }}=5.00 \mathrm{MPa}, T \approx 32^{\circ} \mathrm{C}$.

[3] Sou, A., Maulana, M. I., Hosokawa, S., and Tomiyama, A., 2008. "Ligament formation induced by cavitation in a cylindrical nozzle". Journal on Fluid Science and Tehnology, 3, pp. 633-644.

[4] Soteriou, C., Andrews, R., and Smith, M., 1995. "Direct injection diesel sprays and the effect of cavitation and hy- draulic flip on atomization". In SAE.

[5] Winklhofer, E., Kelz, E., and Morozov, A., 2003. "Basic flow processes in high pressure fuel injection equipment". In ICLASS.

[6] Payri, R., García, J., Salvador, F. J., and Gimeno, J., 2005. "Using spray momentum flux measurements to understand the influence of diesel nozzle geometry on spray characteristics". Fuel, 84(5), pp. 551-561.

[7] Chang, J. C., Huang, S. B., and Lin, C. M., 2006. "Effects of inlet surface roughness, texture, and nozzle material on cavitation". Atomization and Sprays, 16, pp. 299-317.

[8] Badock, C., Wirth, R., Fath, A., and Leipertz, A., 1999. "Investigation of cavitation in real size diesel injection nozzles". International Journal of Heat and Fluid Flow, 20, pp. 538-544.

[9] Roosen, P., 2000. "Investigation of the transient behaviour of cavitation effects in liquid injection nozzles". Transient phenomena in multiphase and multicomponent systems : research report, pp. 72-83.

[10] Winklhofer, E., Kull, E., Kelz, E., Morozov, A., and Zurich, S., 2001. "Comprehensive hydraulic and flow field documentation in model throttle experiments under cavitation conditions". In ILASS-Europe Annual Meeting, pp. 574579.

[11] Tseng, Q. Piv (particle image velocimetry) — imagej plugin - https://sites.google.com/site/qingzongtseng/piv.

[12] Tseng, Q., Duchemin-Pelletier, E., Deshiere, A., Balland, M., Guillou, H., Filhol, O., and Théry, M., 2012. "Spatial organization of the extracellular matrix regulates cellcell junction positioning". Proceedings of the National Academy of Sciences, 109(5), pp. 1506-1511.

[13] Ndiaye, E. H. I., Bazile, J. P., Nasri, D., Boned, C., and Daridon, J. L., 2011. "Private communication". (Laboratoire des Fluides Complexes et leurs Réservoirs, UMR CNRS 5150, Université de Pau).

[14] Mauger, C., Méès, L., Michard, M., and Valette, S., 2011. "Etude d'un écoulement de canal cavitant par plusieurs techniques optiques". Fluvisu14.

[15] Hiroyasu, H., 1991. "Break-up length of a liquid jet and internal flow in a nozzle". ICLASS-91, pp. 275-282.

[16] Hiroyasu, H., 2000. "Spray breakup mechanism from the hole-type nozzle and its applications". Atomization and Sprays, 10(3-5), pp. 511-527.

[17] Balenwski, B., Heine, B., and Tropea, C., 2010. "Experimental investigation of the correlation between nozzle flow and spray using laser doppler velicimeter, phase doppler system, high-speed photography, and x-ray radiography". Atomization and Sprays, 20(1), pp. 57-70.

[18] He, L., and Ruiz, F., 1995. "Effect of cavitation on flow and turbulence in plain orifices for high-speed atomization". Atomization and Sprays, 5, pp. 569-584.

[19] Sou, A., Hosokawa, S., and Tomiyama, A., 2007. "Effect of cavitation in a nozzle on liquid jet atomization". International Journal of Heat Transfer, 50, pp. 3575-3582. 